\title{
SOME REMARKS ON DIFFERENTIAL DIAGNOSIS OF BLOOD DISEASES.
}

\author{
By A. PINEY, M.D., M.R.C.P. \\ (Assistant Physician, St. Mary's Hospital for Women and Children.)
}

Differential diagnosis of blood diseases has been discussed time and again, but, as a rule, blood-pictures, rather than clinical features, have been taken into account, so that the impression has become widespread that the whole problem is one for the laboratory, rather than for the bed-side. It is obvious, however, that the first steps in diagnosis must be based on clinical signs and symptoms. In this paper, therefore, certain outstanding clinical features of blood diseases, and various rather puzzling syndromes will be described.

The outstanding external sign that leads the practitioner to consider the possibility of a blood disease is pallor, which is not quite so simple a state as is often supposed. It is, of course, well known that cutaneous pallor is not an infallible sign of anæmia, but it is often presumed that well-coloured mucous membranes are fairly good evidence that anæmia is not present. This is not necessarily true. The conjunctivæ may be bright pink in spite of anæmia, because mild inflammation may be present, masking the pallor. This is quite frequently due to irritation by eyelash dyes. Similarly, the finger-nails, which used to serve as a reliable index of pallor, are now found disguised with coloured varnish. The mucous membrane of the pharynx may be misleading because reddened, for example, by the irritation of cigarette smoking. The classical external signs of anæmia are thuse no longer dependable.

The colour of the palm of the hand, except in manual workers, is probably the best clinical index of pallor or its absence. The tint of the lobe of the ear as seen by transillumination is also quite dependable.

Intense pallor may be accompanied by only the slightest of symptoms. Thus, it has often been remarked that the severity of the symptoms in pernicious anæmia seems to be disproportionately slight when the low red count and the intense pallor are considered. This is, of course, due to the characteristic megalocytosis. Many of the red corpuscles are functionally as well as morphologically giants, and so a relatively small number may suffice for adequate oxygenation of the tissues. In microcytic anæmias, on the other hand, the symptoms may be quite severe even at a time when the number of red corpuscles is relatively high, because the majority of the corpuscles are not only small, but each one has a defective complement of hæmoglobin. These characters of the two great groups of anæmias are quite well known, but what is less commonly recognised is that very slight reduction in the number of red corpuscles, whatever the cause, does not, by itself, produce symptoms. When, therefore, a patient with, say, 4,000,000 red corpuscles per c.mm. complains of symptoms, it is rare for these to be due to poverty of the blood. Far more commonly, symptoms, in such circumstances, result from some associated condition, perhaps from the same factor as that which has caused the slight anæmia.

Simple pallor is not the only cutaneous change that should be looked for in suspected cases of blood disease. Thus, the ashen pallor of chronic nephritis, with puffiness of the eyelids, is not necessarily a sign of anæmia. It is much more commonly associated with an increased blood volume. 
Slight icterus must not be overlooked. Faint jaundice of the scleræ is common in pernicious anæmia, but, strangely enough, the slightest degrees of icterus are best seen on the soft palate. Daylight is essential for the examination, which often reveals a faint yellow colour of the mucosa alongside the uvula, even when the scleræ are quite unaffected.

The greyish tinge of the skin that occurs in advanced malignant disease has only to be seen to be recognised, although it has some resemblance to the more definitely grey pallor that develops in the late stages of leukæmia.

Further, the bright red colour of the skin and mucosæ that occurs in polycythæmia must be distinguished from the bluer tinge of cyanosis. Once the pure red colour of the former condition has been recognised, confusion is almost impossible.

No examination of the skin is complete without an inspection of the nails. Their condition is often overlooked, although the importance of spoon-nails in the diagnosis of achylic anæmia is well known.

Retinal Hæmorrhages and Infiltrations. Ophthalmoscopic examination should never be neglected. The colour of the fundus is often instructive, and it is surprising how pink it may be, even in patients with almost blanched mucous membranes. Hæmorrhages should be noted and care must be taken not to overlook small areas of bleeding at the extreme periphery of the retina: a common position in the early stages of many forms of purpura. These, of course, are simple hæmorrhages which may be relatively bright red because recent, or may be dark brown through changes in the hæmoglobin. If, however, a hæmorrhagic area is surrounded by a greyish, yellow or pink zone, it is not due to simple bleeding, but is a result of some form of infiltration, the commonest being leukæmic. Very rarely the ophthalmoscope may reveal the fact that an acute leukæmia, which has already been recognised as such by blood examination, is really an example of chloroma, the infiltrations in the retina being bright green; or there may be a green ring round hæmorrhagic areas.

Next in importance to pallor are petechiz. The examination of the skin in any case suspected of being a blood disease must include a careful search for hæmorrhages. These may occur in any position and are not particularly related to pressure points. Even if the most careful examination fails to reveal any petechiæ, an attempt should be made to produce them artificially; thus, if the cuff of the sphygmomanometer is inflated to a little below the systolic pressure and left for five minutes, petechiæ will be found on the forearm in all cases of considerably increased capillary permeability. There may be very few petechiæ as a result of this test, but if there are none, even on the nail bed, it can be taken for granted that the capillaries are relatively healthy.

It is obvious that larger hæmorrhages should be sought for, but they are, of course, much less likely to escape observation than are the minute petechiæ.

A point to be borne in mind in the clinical assessment of the possible cause of a hæmorrhagic disease is that the degree of ill-health is not necessarily of any significance. Many patients with thrombocytopenic purpura are in good health, and remain so, even without treatment, for many years. Conversely, there may be a severe degree of illness with very little external sign of bleeding. Some cases of thrombocytopenic purpura present a mild degree of fever and malaise for some days, or even weeks, before hæmorrhages appear. Equally, however, leukæmia may start as a hæmorrhagic disease at a time when the patient appears well. 
To reach a diagnosis simply from examination of petechiæ and other cutaneous hæmorrhages is not possible. They may be due to a great variety of causes.

A few remarks on the examination of cutaneous hæmorrhages may be useful. First, if the hair follicles are involved it is not likely that the case is one of thrombocytopenic purpura. Secondly, the size and distribution of the hæmorrhages has otherwise no significance, but the feeling of the skin at the sites of hæmorrhage may be of importance. Thus, if each petechial spot appears to be surrounded by a small raised area with a definite edge, one is dealing with a form of purpura due to an increase of permeability in the capillary walls sufficient to permit exudation of plasma, but of only few red corpuscles. The two well-known examples of such a state are Henoch's and Schönlein's purpura. These two diseases, which used to be regarded as distinct, are now recognised as both being manifestations of allergy. They are, therefore, best classed together under the name anaphylactoid purpura.

It is important to recognise the almost urticarial character of the hæmorrhages in this type of purpura because it presents many points of importance. There are no distinctive changes in the blood, although occasionally there may be an increase of eosinophils. From the point of view of prognosis, these syndromes must be distinguished from other forms of purpura because the outlook is invariably good. Even if cutaneous hæmorrhages are accompanied by bleeding from the bowel and by hæmaturia, recovery is invariable. Bleeding from the internal organs in these syndromes is not due to simple hæmorrhage, but is the result of acute hæmorrhagic inflammation; thus, in the hæmaturia that may complicate these syndromes, casts will be found in the urine, and yet recovery will be complete. This is probably the only form of acute hæmorrhagic nephritis in which the kidney never suffers permanent damage. Similarly the hæmorrhagic colitis completely disappears.

Enlargement of the Spleen is another sign which will almost certainly lead to blood examination. For our present purpose, it is necessary to realize that not all forms of splenomegaly are due to blood disease. Thus, discovery of an enlarged spleen should not immediately lead to blood examination. Other causes should first be excluded; for example, of the adult patients with palpable spleens who have been sent to me as blood dyscrasias during the past ten years, I7 per cent. have been suffering from chronic cardiac failure. Clearly then, cases of moderate enlargement of the spleen, at least in adults, should first be considered from the cardiological aspect.

It is convenient to divide cases of splenic enlargement into two groups, viz., those associated with enlargement of superficial lymphatic glands; and those without such enlargement. The first group are almost invariably examples of some form of blood disease. The common ones in this category being lymphadenoma and lymphatic leukæmia ; far less commonly, tuberculosis of the spleen accompanies generalized tuberculous infection of lymphatic glands. The differentiation between these three conditions can be based on histological examination of excised glands or on ordinary blood examination. The only diagnostic difficulty that may arise is that the blood picture of chronic glandular tuberculosis may be almost indistinguishable from that of chronic lymphatic leukæmia. Sternal puncture permits of accurate differentiation.

The second group contains those cases in which the spleen is enlarged, but no glandular involvement can be detected. Here the differential diagnosis in individual cases may be extremely difficult, partly because there are so many possible 
causes for such a condition, and partly because there may be no definite signs elsewhere. It is not sufficient to suppose that because a spleen is very large, the case must be one of chronic myeloid leukæmia, because, although rarely, enormous spleens are found in other maladies. Conversely, it is also not safe to suppose that a moderate enlargement of the spleen cannot be due to chronic myeloid leukæmia. It is indeed true to state that no useful diagnostic inferences can be drawn from size alone.

Associated symptoms should always be sought for; thus, a patient who presents himself with an abdominal swelling which, on examination, proves to be an enlarged spleen, requires systematic examination.

No case of splenomegaly should be left without an examination of the skeleton. It is rare for the spleen to be notably enlarged in cases of multiple myeloma, but it does occur, and therefore examination of the bones in all cases of splenomegaly should be gentle, as spontaneous fractures may be caused by clumsy handling.

Tenderness on percussion of the sternum, even if the spleen is not enlarged, is almost pathognomonic of leukæmia. Indeed, of the clinical signs of leukæmia, probably the most dependable is such tenderness of the sternum (Mosler's sign).

As a rule, tenderness is more marked in myeloid than in lymphatic cases; this is probably due to erosion of the thin anterior wall of the sternum by masses of proliferating cells, and obviously, such an affection of the bone marrow will be more intense in myeloid leukæmia. If the sign be present in cases of the chronic lymphatic type, it is usually indicative of an advanced stage of the disease.

Painful spleens are not, as a rule, due to any type of blood disease. They are mostly commonly the result of infection, and, further, it is rare for painful spleens to be greatly enlarged. Acute peri-splenitis is, however, common in the leukæmias, especially in the chronic myeloid type. It is almost invariably due to infarction, which naturally produces an acute peri-splenitis. Chronic peri-splenitis also occurs ; for example, in Banti's disease, but gives rise to no clinical signs.

Not all infective enlargements of the spleen are painful and not all are associated with pathognomonic changes in the blood. Thus, for example, an absolutely normal blood-picture may accompany the splenomegaly due to thrombosis of the splenic vein.

An interesting case, which probably would not have presented so much difficulty had a more characteristic history been available, was that of a lady, aged 39, who had felt easily tired for some ten years. She had spent a year or two in India, but, apart from concussion due to a fall from a horse, had had no illness there. In March I934, she was jaundiced and a diagnosis of acute cholecystitis was made. Prior to the operation she is said to have been anæmic and her white cells are said to have been low, but no figures were available. On the 29th July I934, I saw her in consultation. Her spleen was enlarged, reaching the umbilicus, and the lower edge of the liver was palpable. Her temperature was $99^{\circ}$, and I was informed that it had been varying between $98^{\circ}$ and $100.6^{\circ}$ for months. Her leucocyte count was 2,000 per c.mm., the monocytes (large hyaline leucocytes) being 20 per cent.

The doctor I met in consultation over the case was of opinion that this might be an example of chronic agranulocytosis, but such a view would not, of course, explain the enlargement of the liver and spleen. A liver puncture was therefore performed and Leishman-Donovan bodies were found. 
This case is mentioned only to call attention to the importance of Kala-Azar as a cause of chronic leucopenia with splenomegaly.

Simple smooth enlargement of the spleen not associated with any signs of heart failure or any change in the blood, may be an example of Gaucher's disease. It is important to recognise this malady, because, as a rule, without treatment, it interferes little with normal activity and does not greatly shorten life. This statement, however, does not apply to those cases in which the skeleton as well as the spleen is extensively involved. The outlook then is definitely worse and it must be emphasised that removal of the spleen accelerates the disease-process, which is, after all, an inborn error of metabolism. If then, the spleen is not available for storing the abnormal metabolites, they will be stored in the bone marrow.

Then also, there is a form of Gaucher's disease in which the bulk of the storage occurs in the bones, often leading to spontaneous fractures. The spleen may not present enlargement for some years, and, in this type of the disease, it is even more dangerous to remove the spleen, as the rate of storage of the Gaucher substance in the skeleton is further increased, and pathological fractures become even more frequent.

The infiltration of the bones in Gaucher's disease does not at first cause tenderness on percussion, but is associated with dull aching pains, especially at night. Later, tenderness may be extreme. This is an important point in distingushing the skeletal type of Gaucher's disease from multiple myeloma, because, in the latter, the bones are tender on percussion from the earliest stage of the disease. Another differential point of interest is that the skeletal type of Gaucher's disease invariably presents a familial incidence, whereas multiple myeloma does not appear to arise as a result of any inherited abnormality. Familial incidence may occur in theo splenomegalic type of Gaucher's disease, but is not as well marked as in the? skeletal type.

This paper will not discuss the time-honoured differentiation between the various swellings that may present themselves in the left hypochondrium. It will be taken for granted that, as a general rule, a spleen can be recognised as such by careful palpation. If this be admitted, it is possible to divide enlarged spleens into those that present a smooth surface and those that have an irregular one. The former are far commoner; the latter condition is almost pathognomonic of Hodgkin's disease. Very rarely it may be due to deposits of primary or secondary sarcoma.

The mobility or fixity of the spleen is of no differential diagnostic importance.

In brief, it may be said that the significance of an enlarged spleen can, in the great majority of cases, be reasonably accurately assessed, but only if associated physical signs are carefully elicited and taken into account.

Chronic fatigue accompanied by slight reduction in the number of red corpuscles quite often results from intestinal worms. In such cases, and indeed in all suspected disorders of the blood, a complete differential leucocyte count is necessary. If there be any considerable degree of eosinophilia, the probability of helminthic infestation is considerable.

It is necessary to call attention to two sources of confusion here. First, chronic fatigue, slight anæmia and eosinophilia may be the earliest signs of abdominal Hodgkin's disease; even when no superficial glands are enlarged. Secondly, it has unfortunately become customary to treat almost every anæmic person with injections of liver extract, whether or not an accurate diagnosis of pernicious 
anæmia has first been made. Liver treatment benefits only certain of the megalocytic anæmias, but, if given over a period of weeks, it will evoke an increase in the number of eosinophiles in anyone. In evaluating the significance of eosinophilia, these sources of confusion must be borne in mind.

Another cause of slight anæmia accompanied by symptoms out of proportion to the reduction in the number of red corpuscles is the presence of a malignant tumour, especially of the intestinal tract. It is surprising how often an early carcinoma of the rectum, which is giving rise to no local symptoms, may cause ill-health and a moderate hypochromic anæmia. Routine examination of the rectum cannot be carried out on every patient, but it should never be omitted in obscure cases of anæmia.

Equally important is investigation of the gastric juice. The achylia of pernicious anæmia is well known, and the presence of free acid in the stomach is almost conclusive evidence against the diagnosis. This is not, however, the only importance of gastric examination. The achlorhydria of the anæmia of middleage and of the Plummer-Vinson syndrome are rarely forgotten, but chemical changes suggestive of gastric malignancy may be the first explanation of a slight hypochromic anæmia. It is fortunate that malignant tumours in the less accessible parts of the intestine rarely produce anæmia, at any rate in their early stages. There is, therefore, little excuse for overlooking those neoplasms which are known to be of importance in the ætiology of anæmia.

Persistent fatigue without physical signs warrants blood examination. It is quite surprising how many patients with unexplained and indefinable malaise are found to have moderate leucopenia with relative lymphocytosis. Such a chronic hypogranulocytic state usually responds to treatment, with great improvement in the symptoms.

A brief description of a few cases will illustrate some of the important points:

A boy, aged 5, had been noticed to bruise very easily for the last six months. He was otherwise well, and the only abnormality detected on clinical examination was a very faint yellowish colour of the skin and a positive tourniquet test. His blood showed only 82,000 platelets per c.mm. Many of the platelets were abnormal in shape and a few were strikingly large. This was, thus, a typical case of thrombocytopenic purpura.

A man, aged 69, noticed extensive bruising and a few petechiæ on his legs. The gums were sore, the spleen was not enlarged, there was no tenderness on percussion of the sternum, and there was no leukæmic retinitis. His blood showed:-

Red corpuscles

Hæmoglobin

Leucocytes

$$
\begin{array}{rrrrrr}
\ldots & \ldots & \ldots & \ldots & \ldots & 2,400,000 \text { per c.mm. } \\
\ldots & \ldots & \ldots & \ldots & \ldots & \ldots 48 \text { per cent. } \\
\ldots & \ldots & \ldots & \ldots & \ldots & .5,900 \text { per c.mm. }
\end{array}
$$

Neutrophiles:

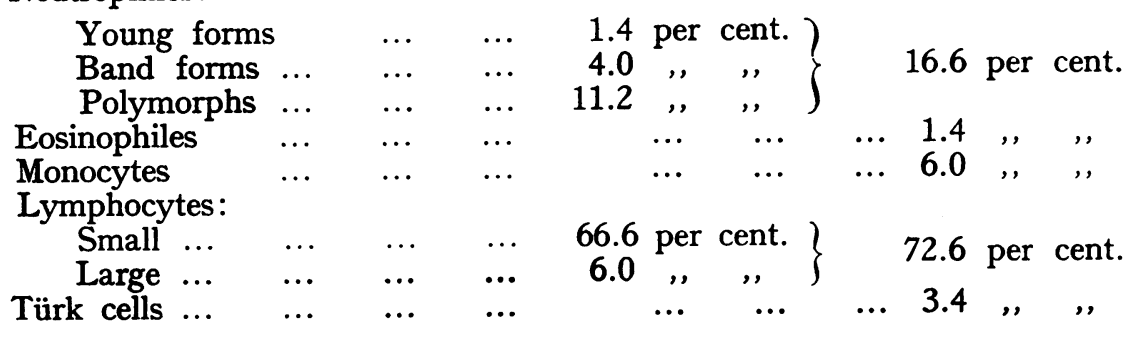


There were 54,000 platelets per c.mm. The picture, therefore, was suggestive of chronic lymphatic leukæmia, unusual as it is to find so low a platelet count in the chronic form of the disease. He was treated by intramuscular injections of liver, and, within two months, the hæmorrhagic tendency ceased. Seven months after I first saw this patient, he developed all the signs of acute lymphatic leukæmia, viz., hæmorrhages, sore mouth, retinitis and glandular enlargement, but at no time did his leucocytes exceed 6,500 per c.mm., even in the terminal phase, when all the white cells were lymphoblasts.

A similar case was that of a woman, aged 50, who had had profuse hæmaturia a few days before I saw her. It appeared that she had noticed that she bruised easily during the last few months. No petechiæ were present, but they could easily be produced by the tourniquet test. Her platelet count was 42,000 per c.mm. and, when the platelets rose to normal numbers, the hæmorrhagic tendency ceased.

These cases may be compared with that of a man, aged 67 , whose history was as follows: Two years before he consulted me, he had had two attacks of hæmaturia. Prior to that he had been treated for sciatica. When I saw him there were extensive bruises and petechiæ, especially on the legs, where they involved the hair follicles. The tourniquet test was positive, the spleen was not enlarged and no glands could be felt. This, clinically, might have been a case of thrombocytopenic purpura, although the involvement of hair-follicles was surprising. Blood examination shewed 30,000 leucocytes per c.mm. of which 60 per cent. were monocytes. The platelets numbered I9,000 per c.mm. This was thus a case of sub-acute or chronic monocytic leukæmia. It is interesting to note that, even in this case, the occurrence of spontaneous hæmorrhages was controlled by injections of adrenalin, which caused a great but transient increase in the number of platelets

Hæmorrhages of any kind, even if the skin is not involved, may also be of great importance as early signs of some blood disease. For example, a previously healthy man, aged 46, had sudden severe abdominal pain and vomited a large quantity of blood. X-ray examination showed no evidence of gastric ulcer, and no other important physical signs were detected. His red corpuscle count, which prior to the hæmorrhage was presumably normal, fell to $2,500,000$ per c.mm. His leucocyte count at this time was 20,000 per c.mm. with the typical variegated picture of chronic myeloid leukæmia. Within a few months he developed a large spleen and ultimately, in spite of X-ray treatment, died. It was interesting to note that he developed an attack of acute gout in his right big toe after quite a small dose of X-rays.

It is often supposed that hæmorrhages, usually of the skin, are an essential part of the picture of acute leukæmia. This is not always so.

A woman, aged $3 I$, in apparently perfect health, dined not wisely but too well, and vomited during the night. The next day she felt unwell and found that her temperature was $99^{\circ}$. For two days she continued to feel unwell, and on the fourth day sent for her doctor who was unable to find any abnormality. Her temperature became normal, but she still had slight nausea. On the fourteenth day, a Widal test was performed and was negative. A blood film taken at the same time shewed an enormous increase of white cells. The figure proved to be 620,000 leucocytes per c.mm., of which 92 per cent. were myeloblasts. Re-examination of the patient showed only one sign suggestive of leukæmia, viz., tenderness on percussion of the sternum. The patient died on the sixteenth day during a series of convulsions. 
Another case presenting most puzzling signs was that of a man, aged 37, who six months before I saw him, complained of a pain in the left leg. His doctor made a diagnosis of lymphangitis, and, with treatment, the pain disappeared, but the patient still felt unwell. Ten days before I saw him in consultation, he had started to run a temperature varying between $100^{\circ}$ to $103^{\circ}$. A leucocyte count was performed, simply because the doctor was not able to think of any reasonable explanation for the fever. It was found that there were 600,000 leucocytes per c.mm. the great majority of which were myeloblasts. When I saw the patient, his temperature was normal and the only sign suggestive of myeloid leukæmia was tenderness on percussion of the sternum. Nevertheless, this was quite obviously a case of sub-acute or acute myeloid leukæmia. Only after a month did he develop any petechiæ, and, strange to say, these disappeared again in spite of the fact that his blood-picture was unchanged and the tenderness of his sternum had not changed. At this time, ordinary clinical examination would have failed to detect any other sign of disease in this patient.

It may be useful to emphasise the fact that various forms of leukæmia may first present themselves in most surprising ways; thus, a woman aged 52 , with no previous history of ill-health, presented herself with swelling of the ankles and pain in the arms. No clinical signs suggestive of leukæmia were detected, but her leucocyte count was I20,000 per c.mm. with the typical variegated blood picture of chronic myeloid leukæmia. She died two and a half years later.

Again, a man of 6o, complained of persistent diarrhœa for which no cause was found; he then developed slight jaundice but neither enlargement of the spleen nor lymphatic glands could be discovered. His leucocyte count at this time was 5,000 per c.mm. with 98 per cent. of lymphocytes.

An onset very much suggestive of acute leukæmia may be due to other causes ; thus a lady, aged 26, developed an attack of "influenza". Her temperature, during a period of twelve days, varied from $99^{\circ}$ to $104^{\circ}$. Enlarged glands were found in her neck and groins, the spleen was just palpable and the mouth was sore. This might well have been suspected as being a case of acute leukæmia. Her leucocyte count was 15,000 per c.mm. and the differential count showed:-

$\begin{array}{llllllll}\text { Leucocytes } & \ldots & \ldots & \ldots & \ldots & \ldots & \ldots & 15,000 \text { per c.mm. }\end{array}$

Neutrophiles:

Band forms $\quad \ldots \quad \ldots \quad \ldots \quad \ldots$

Polymorp
Monocytes ...

(large hyalines)

Lymphocytes:

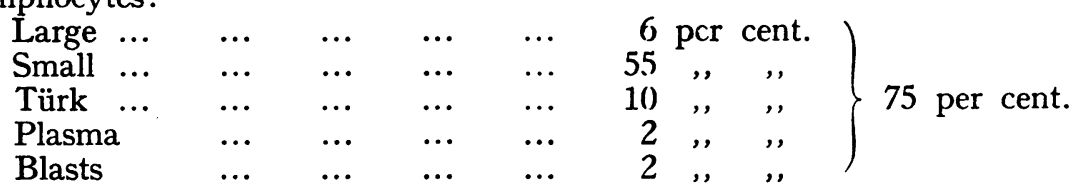

No abnormalities of red corpuscles. All the lymphocytes, even those that were not definite Türk cells, showed excessive basophilia of the cytoplasm.

This was, therefore, a typical case of glandular fever (acute infectious mononucleosis), and the patient made an uninterrupted recovery. 
A similar case occurred in a man, aged 27, in whom a diagnosis of acute lymphatic leukæmia had been made. The patient realised the gravity of the disease and, after he had put his affairs in order, a diagnosis of glandular fever was made, and an uninterrupted recovery ensued.

An interesting and important hæmatological point is that in glandular fever there is great increase in the number of mononuclear cells, but blood films do not present the same monotonous appearance as that seen in lymphatic leukæmia. The mononuclear cells vary considerably in size and many of them show wellmarked basophilia of the cytoplasm. This is almost pathognomonic of the disease. The only other malady in which such cytoplasmic basophilia occurs, is the very rare plasma-cell leukæmia. Admittedly, in German measles a considerable number of plasma-cells with typical basophilic cytoplasm are present, but other mononuclear cells are normal in appearance. The point about glandular fever is that all types of mononuclear cells may show such basophilia.

The general examination of the body surface must be complete, even in those cases in which the diagnosis has already been made.

The importance of small physical abnormalities is shown by the following case :- a woman, aged 46 , whose father had died of pernicious anæmia, herself developed the disease. Her red corpuscles were I,5I5,000 per c.mm., with a colour index of I.2. She was given large doses of liver extract by injection, and, within three weeks, her red corpuscles had fallen to $I, 085,000$. It was, therefore, supposed that the diagnosis of pernicious anæmia might be wrong. Further investigation showed complete achylia gastrica, so that it seemed almost certain that the diagnosis was correct. When I saw her in consultation with her doctor, I was struck by her rather lethargic mentality and by the almost complete absence of the outer third of her eyebrows. She had the general appearance of a typical case of mild hypothyroidism. At my suggestion the liver extract was continued, but, in addition, small doses of thyroid were given. On the eighteenth day after the beginning of this treatment her hæmoglobin was 54 per cent., and it steadily rose to normal.

A striking point about this case, which is extremely common in pernicious anæmia, was the patient's statement that her hair started to go grey at the age of twenty. She had six brothers and sisters none of whom had developed premature greyness or pernicious anæmia. Of course, premature greyness may be unassociated with anæmia, either pernicious or achylic, but absence of premature greyness is so unusual in pernicious anæmia as to justify doubt as to the diagnosis.

It has, of course, been impossible in this paper to do more than call attention to some of the points of clinical importance in blood diseases. The common view that the subject is one exclusively for the attention of the laboratory worker has led to much neglect of clinical observation in these maladies. The purpose of the present paper will have been served if the reader realises that blood diseases lie within the province of the general physician: only special hæmatological investigations, like all other technical procedures, require the arts of the trained laboratory worker. 